\title{
PROPERTIES OF THE AMNIOTIC MEMBRANE FOR POTENTIAL USE IN TISSUE ENGINEERING
}

\author{
Hassan Niknejad ${ }^{1,2}$, Habibollah Peirovi ${ }^{1}$, Masoumeh Jorjani ${ }^{1,2^{*}}$, Abolhassan Ahmadiani ${ }^{2}$, Jalal Ghanavi ${ }^{1}$, Alexander \\ M. Seifalian ${ }^{3}$ \\ ${ }^{1}$ Department of Nanomedicine and Tissue Engineering, ${ }^{2}$ Department of Pharmacology \& Neuroscience Research \\ Center, Shaheed Beheshti Medical University, Tehran, Iran. \\ ${ }^{3}$ Biomaterials and Tissue Engineering Centre (BTEC), Academic Division of Surgical and Interventional Sciences, \\ University College London, London, UK
}

\begin{abstract}
An important component of tissue engineering (TE) is the supporting matrix upon which cells and tissues grow, also known as the scaffold. Scaffolds must easily integrate with host tissue and provide an excellent environment for cell growth and differentiation. Most scaffold materials are naturally derived from mammalian tissues. The amniotic membrane (AM) is considered an important potential source for scaffolding material. The AM represents the innermost layer of the placenta and is composed of a single epithelial layer, a thick basement membrane and an avascular stroma. The special structure and biological viability of the AM allows it to be an ideal candidate for creating scaffolds used in TE. Epithelial cells derived from the AM have the advantages of stem cells, yet are a more suitable source of cells for TE than stem cells. The extracellular matrix components of the basement membrane of the AM create an almost native scaffold for cell seeding in TE. In addition, the AM has other biological properties important for TE, including anti-inflammatory, anti-microbial, anti-fibrosis, anti-scarring, as well as reasonable mechanical property and low immunogenicity. In this review, the various properties of the AM are discussed in light of their potential use for TE.
\end{abstract}

Keywords: Amniotic membrane, tissue engineering, scaffold, amniotic epithelial cells.

*Address for correspondence:

Masoumeh Jorjani

Department of Pharmacology \& Neuroscience Research

Center,

Shaheed Beheshti Medical University,

P.O. Box 19615-1179, Tehran, Iran.

Telephone Number: +98-21 22429768

FAX Numberax: +98-21 22424212

E-mail: mjorjani@sbmu.ac.ir

\section{Introduction}

Tissue engineering (TE) is defined as the development of biological substitutes for the purpose of restoring, maintaining or improving tissue function and requires the application of principles and methods from both engineering and life sciences (Langer and Vacanti, 1993). Scaffolds are developed to support the host cells during TE, promoting their differentiation and proliferation throughout their formation into a new tissue. Therefore, the design and selection of the biomaterials used for scaffolding is a critical step in TE (Mano et al., 2007). During TE, cell seeding onto scaffolds is the first step in establishing a three-dimensional culture, and plays a crucial role in determining the progression of the tissue formation (Vunjak-Novakovic et al., 1998). Successful cell seeding of the scaffold depends on the type and source of the living cells as well as the extracellular matrix (ECM) components of the scaffold.

One of the oldest biomaterials used for scaffolds is the foetal membrane. The foetal membrane was first used for the transplantation of skin in 1910 (Davis, 1910). Subsequently the foetal membrane was found to be useful in the management of burns; creation of surgical dressings; as well as reconstruction of the oral cavity, bladder, and vagina; tympanoplasty; arthroplasty and so forth (Fernandes et al., 2005). Specifically, the amniotic membrane (AM) has gained importance because of its ability to reduce scarring and inflammation; enhance wound healing; and serve as a scaffold for cell proliferation and differentiation as a result of its antimicrobial properties. In addition, the ECM of the AM and its components, such as growth factors, suggest that the AM is an excellent candidate to use as a native scaffold for TE. In addition, the AM is a biomaterial that can be easily obtained, processed and transported.

In this review, we will describe the necessary components of tissue engineering, including the potential cells used for differentiation and the properties of a scaffold which would be best suited for the purposes of TE. We then describe the basic structure and properties of the AM that make it an excellent candidate to use as scaffolds in TE.

\section{Anatomy and histology of the amniotic membrane}

Amniotic membranes develop from extra-embryonic tissue and consist of a foetal component (the chorionic 


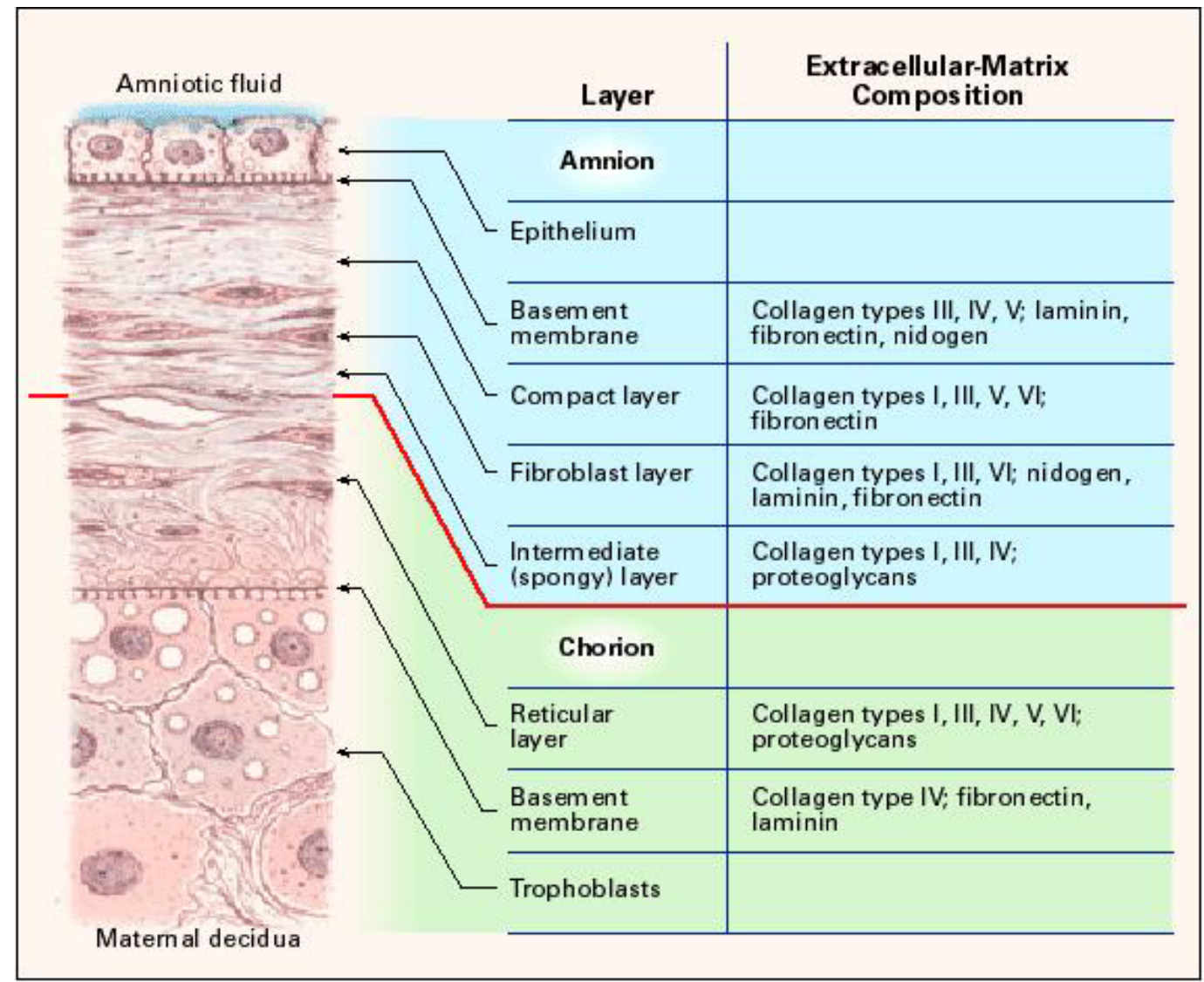

Figure 1: Schematic presentation of the structure of the foetal membrane at term. The Extracellular matrix components of each layer are shown. Adapted from Parry and Strauss (1998); with some modifications.

plate) and a maternal component (the deciduas). These two parts are held together by the chorionic villi and connect the cytotrophoblastic shell of the chorionic sac to the decidua basalis. The foetal component, which includes the amniotic and chorionic foetal membranes, separates the foetus from the endometrium. The amniochorionic membrane forms the outer limits of the sac that encloses the foetus, while the innermost layer of the sac is the AM. The AM consists of an epithelial monolayer, a thick basement membrane, and an avascular stroma (Fig. 1). The AM contains no blood vessels or nerves; instead, the nutrients it requires are supplied directly by diffusion out of the amniotic fluid and/or from the underlining decidua. The innermost layer, nearest to the foetus, is called the amniotic epithelium and consists of a single layer of cells uniformly arranged on the basement membrane. The basement membrane is one of the thickest membranes found in all human tissue. The support provided to the foetus by the basement membrane throughout gestation stands testimony to the structural integrity of this remarkable membrane. The compact layer of stromal matrix adjacent to the basement membrane forms the main fibrous skeleton of the AM. The collagens of the compact layer are secreted by mesenchymal cells situated in the fibroblast layer. Interstitial collagens (types I and III) predominate and form parallel bundles that maintain the mechanical integrity of AM. Collagens type V and VI form filamentous connections between interstitial collagens and the epithelial basement membrane. The intermediate layer (spongy layer or zona spongiosa) of the stromal matrix sits adjacent to the chorionic membrane. Its abundant content of proteoglycans and glycoproteins produces a spongy appearance in histologic preparations, and it contains a nonfibrillar meshwork of mostly type III collagen (Parry and Strauss, 1998). The spongy layer is loosely connected to the chorionic membrane; hence, the AM is easily separated from the chorion by means of blunt dissection.

\section{The main sources of stem cells currently used for TE}

The use of stem cells is an intrinsic part of TE and plays a key role in the creation of implantable tissue. The source of cells utilized in TE can be autologous, meaning from the patient himself, allogenic, meaning from a human donor not immunologically identical, or xenogenic, meaning from a different species (Naughton, 2002). Autologous cells represent an excellent source for use in TE because of the low risk of immune complications. However, they are not cost-effective or batch controlled for universal clinical use (Knight and Evans, 2004). In addition, for many patients with extensive end-stage organ failure, a tissue biopsy may not yield enough healthy cells for expansion and transplantation. In contrast, the use of allogenic cells for TE offers advantages over autologous cells in terms of the uniformity, the standardization of procedure, the quality control and the cost-effectiveness (Knight and Evans, 2004). 
Human embryonic stem cells as a source of stem cells for $\mathrm{TE}$

Human embryonic stem cells (HESCs) are an interesting example of allogenic cells that are currently used for TE. HESC lines are derived from the inner cell mass of 3-5day-old blastocysts as originally described by Thomson et al. (1998). HESCs possess high levels of telomerase activity and express the surface markers, SSEA-4, TRA (tumour rejection antigen)-1-60 and TRA-1-81 (Reubinoff et al., 2000). In addition, they also show high expression of octamer binding protein 4 (Oct-4) and Nanog (Reubinoff et al., 2000; Chambers et al., 2003). Using these HESCs, researchers have been successful in generating cells of ectodermal, endodermal, and mesodermal lineage. This differentiation was determined using the formation of embryoid bodies in vitro and teratomas in vivo (Thomson et al., 1998). Teratomas form when embryonic stem cells are injected into severe combined immunodeficient (SCID) mice and tissue types formed include gut epithelium, cartilage, bone and neural epithelium among others (Thomson et al., 1998). In spite of all advantages of embryonic stem cells, they have major limitations for use in TE.

A fundamental bottleneck that must be overcome in order to use stem cells for TE is the limited supply of stem cells (Chai and Leong, 2007). This problem becomes more critical as the engineering of bulk tissues or complex organs is contemplated. Such goals would necessitate the maintenance of large quantities of undifferentiated cells to provide sufficient starting material. With a limited supply of embryonic stem cells, extensive in vitro expansion would be required to obtain a sufficient number of cells for therapeutic purposes. At first, it was assumed that the in vitro expansion conditions for HESC lines were very similar to those used for mouse embryonic stem cells line. However, it was soon discovered that, although mouse embryonic stem cells could proliferate and remain undifferentiated in the absence of fibroblast feeder layer and in the presence of leukemia inhibitory factor (LIF), the same is not true for HESCs (Thomson et al., 1998). LIF maintains mouse embryonic stem cells by activating the STAT3/gp130 pathway. Though treatment of HESCs with exogenous LIF activates the same pathway, this is insufficient to maintain the self-renewal of these cells (Daheron et al., 2004). Thus, HESCs have been mostly derived and cultured on a layer of mouse embryonic fibroblasts (MEFs). The concern over xenogenic contaminants from the mouse feeder cells may be a limiting factor for transplantation to humans (Mallon et al., 2006). For example, it has been reported that HESCs cultured with MEF might take up and express Neu5Gc, a nonhuman sialic acid, capable of inducing an immune response in humans (Martin et al., 2005). In addition to immune restrictions concerning transplantation studies, the mouse feeder layer may be also an unexpected source of variability when trying to control experimental conditions (Heng et al., 2004). Another potential problem of using HESC for transplantation is tumourgenicity. Undifferentiated cells that retain pluripotency give rise to tumours known as teratomas in vivo (Mitjavila-Garcia et $a l ., 2005)$. In addition, the difficulties in obtaining HESCs as well as important ethical concerns make the use of HESCs an improbable candidate for TE (Bobbert, 2006; Lei et al., 2007).

\section{Amniotic epithelium as a source of stem cells for TE}

Amniotic epithelial cells (AECs) have several characteristics that make them a great source of stem cells for TE. Similar to the three germ layers of the embryo, including the ectoderm, mesoderm, and endoderm; the amniotic epithelium derives itself from the epiblast prior to gastrulation (Parolini and Soncini, 2006). This would suggest that the amniotic epithelium might retain a reservoir of stem cells all throughout pregnancy. Recent studies aimed at defining the stem cell-like characteristics of AECs have determined that these cells express the surface markers associated with embryonic stem cell, e.g. SSEA-3, SSEA-4, TRA-1-60, and TRA-1-81. These cells also express pluripotent stem cell-specific transcription factors such as Oct-4 and Nanog (Miki et al., 2005; Miki et al., 2007a). The pluripotency of amniotic cells has been confirmed by formation of a xenogenic chimera from AECs and mouse embryonic stem cells in vitro. This chimera gives rise to cells of all germ layers (Tamagawa et al., 2004). Additional experiments have demonstrated in vitro differentiation of AECs into the three germ layers for cardiac cells (mesodermal lineage), neuronal and glial cells (ectodermal lineage), and pancreatic and hepatic differentiation (endodermal lineage). All of these cells show positivity for specific markers (Miki et al., 2005; Ilancheran et al., 2007). For example, cultivated human AECs demonstrate albumin production, glycogen storage and albumin secretion consistent with alpha1-antitrypsin and other hepatocyte gene expression profiles (Takashima et al., 2004).

Clonogenicity is the ability of a single cell to form a cloned colony and is a key defining function that demonstrates the self-renewal properties of stem cells. AECs are clonogenic and their cloning efficiency is comparable to some HESC lines (Ilancheran et al., 2007). As described previously, teratoma formation is an important limiting factor ascribed to pluripotent HESCs in TE use. While it has been shown that AECs are pluripotent, these cells do not form teratomas when transplanted into the testes of SCID mice (Ilancheran et al., 2007; Miyamoto et al., 2004). This is supported by studies using AECs to repair damaged ocular surfaces (Tseng et al., 1998; Ucakhan et al., 2002; Solomon et al., 2002) or amnion cells to improve congenital lysosomal storage disease (Kosuga et al., 2000). It is possible that the lack of telomerase activity in AECs may contribute to tumour suppression in vivo (Miki et al., 2005; Mosquera et al., 1999). It has also been shown that native AECs express the non-polymorphic, non-classical human leukocyte antigen (HLA-G) (Lefebvre et al., 2000), but lack the polymorphic antigens HLA-A, -B (Class IA) and HLA-DR (Class II) on their surfaces (Sakuragawa et al., 1995). These finding suggest that AECs maybe 
immunologically inert and would have reduced risk of rejection or immune reaction upon transplantation. Another important advantage of AECs over HESCs is related to their method of culturing. These cells can proliferate without needing a second cell type serving as a feeder layer. AECs create their own feeder layer with some cells spreading out at the bottom of the culture dish. This basal layer of AECs that attaches to the culture dish may play the role of an autologous feeder layer, serving as a substrate for attachment or possibly providing secreted factors that help induce or maintain undifferentiated AECs (Miki et al., 2005). The other advantage of AECs is large numbers of these cells. It has been reported that an average yield is more than 100 million AECs per amnion collected (Miki et al., 2005). With attention to the robust proliferation of these cells in the presence of certain growth factors such as EGF, large numbers of stem cells could potentially be available using the amniotic membrane as a source (Terada et al., 2000). In addition, discarding of the amniotic membrane after human Caesarean sections allows scientists to avoid the ethical concerns associated with collecting HESCs.

To isolate AECs, the AM is separated from the underlying chorion by mechanical peeling. After several washes with a buffered saline solution containing antibiotics, the AM is digested using enzymes, such as trypsin, dispase II and a combination of trypsin and EDTA. After digestion, AECs are isolated with centrifugation. It has been reported that separation of AECs using a density gradient is a practical method to select for SSEA-4 positive AECs (Miki et al., 2007b).

\section{The amniotic membrane as a scaffold for TE}

A major prerequisite for choosing a scaffold is its biocompatibility. Biocompatibility is the property of being biologically compatible as a result of not producing a toxic, injurious, carcinogenic, or immunological response in living tissue (Baguneid et al., 2006). Scaffolds must not be destroyed by inflammation yet should be able to react to an appropriate host response (Young et al., 2005). In addition, their mechanical properties should include permeability, stability, elasticity, flexibility, plasticity, and resorbability at a rate congruent with tissue replacement (Yang et al., 2001). Scaffolds should also allow cell adhesion and the potential for delivery of biomodulatory agents such as growth factors and genetic materials (Walgenbach et al., 2001).

The attachment of a cell to a scaffold is largely affected by the components of the scaffold's extracellular matrix (ECM). The presence or absence of certain ECM molecules such as collagen, laminin, fibronectin and vitronectin within any basement membrane has a huge influence on the adhesion and growth of the overlying stem cells. As well as allowing the cells to attach and migrate, the ECM molecules also serve as adhesion ligands, which transmit signals via their interaction at cell surface receptors. Cells detect and respond to numerous features of the ECM, including the composition and availability of the adhesive ligands, the mechanical stiffness of the matrix and the spatial and topological organization of the scaffolds, through surface receptors known as integrins (Sniadecki et al., 2006). Integrins are transmembrane receptors that have an extracellular domain, which bind to the ECM, and an intracellular domain that links to the cytoskeleton. After ligand binding, the integrin receptors are recruited into distinct dot-like or streak-like nano- or microdomains on the cell membrane, called "focal adhesions" (Bacakova et al., 2004). In these regions, the integrins communicate with many specific structural and signalling molecules. Some proteins such as talin, filamin, paxillin or vinculin, act as linkers between the integrin receptors and the cytoplasmic actin of the cytoskeleton. In turn, the cytoskeleton is associated with the nuclear membrane, membranes of cellular organelles as well as with various enzymes. Thus, integrins influence intracellular processes important for cell transport, including endocytosis and exocytosis, as well as the processes of cell proliferation, differentiation or apoptosis (Moiseeva, 2001; Aplin, 2003). The dual nature of adhesion molecules, i.e. their mechanical and signaling activity, indicate that they act as sensors of the ECM environment (sensing both mechanical and biochemical changes in the ECM), regulators of the cytoskeleton, and centres of signal transduction (Burridge and Chrzanowska-Wodnicka, 1996; Geiger et al., 2001). Therefore, a scaffold with the preferred ECM components would be a preferred matrix for TE.

The AM is a scaffold with a template of the ECM. AECs secrete collagen type III and IV and noncollagenous glycoproteins (laminins, nidogen, and fibronectin) that form the basement membrane of the AM (Fig. 1). The spongy layer on the stromal portion of the amnion has an abundance of hydrated proteoglycans and glycoproteins and contains a nonfibrillar network of mostly type III collagen (Parry and Straus, 1998). Perlecan, a large (467 $\mathrm{kDa}$ ) heparan sulphate proteoglycan is an important component of the basement membrane. Perlecan is involved in the binding of growth factors and interacts with various extracellular proteins and cell adhesion molecules (Murdoch et al., 1992).

The AM can be used either with amniotic epithelium (intact AM) or without it (denuded AM). To remove the amniotic epithelium, the AM is incubated in EDTA at $37^{\circ} \mathrm{C}$ and the cells are gently scraped with a cell scraper under a microscope. Although complete removal of cellular components from AM is important for the denudation protocol, the structural components of the remaining scaffold must be retained. It has been determined that a detergent-based protocol with sodium dodecyl sulphate (SDS) can remove amniotic epithelium from AM while maintaining the histoarchitecture of the matrix (Wilshaw et al., 2006).

While the use of fresh AM for transplantation in humans has been described, special processing and sterilization is recommended to ensure consistent quality and preservation of the AM. Various methods have been used to preserve the AM including hypothermic storage (at $4{ }^{\circ} \mathrm{C}$ ), freeze drying, $\gamma$-sterilization, glycerolpreservation and cryopreservation. The influences of these different preservation methods on the viability of cells and 
Table 1: Summary of potential applications of the amniotic membrane scaffolds for different tissues in animal or human studies.

\begin{tabular}{|l|l|l|l|}
\hline Reference & The AM component & Species & target cell/tissue \\
\hline Azuara-Blanco et al., 1999 & Cryopreserved AM & Human & Eye \\
\hline Chen et al., 2000 & Cryopreserved AM & Human & Eye \\
\hline Davis, 1910 & Intact AM & Human & Skin \\
\hline Ishino et al., 2004 & Denuded AM & Rabbit & Eye \\
\hline Jin et al., 2007 & Intact/Denuded AM & Rabbit & Cartilage \\
\hline Kosuga et al., 2000 & AECs & Mouse & beta-glucoronidase secretory cell \\
\hline Mligiliche et al., 2002 & Denuded AM & Rat & Peripheral nerve \\
\hline Mohammad et al., 2000 & Denuded AM & Rat & Peripheral nerve \\
\hline Takashima et al., 2004 & AECs/Intact AM & Mouse & Hepatocyte \\
\hline Tsai et al., 2007 & Cryopreserved AM & - & Endothelial cell \\
\hline Tseng et al., 1998 & Cryopreserved AM & Human & Eye \\
\hline Ucakhan et al., 2002 & Nonpreserved AM & Human & Eye \\
\hline Yang et al., 2006 & Denuded AM & Mouse & Skin \\
\hline
\end{tabular}

The AM can be used either with amniotic epithelium (intact) or without it (denuded), preserved or alone. In some studies, prior to preservation, the cells have been removed from the AM. AM: amniotic membrane, AECs: amniotic epithelial cells.

growth factors of the AM are yet to be determined. It has been determined that storage of the AM in glycerol at $4{ }^{\circ} \mathrm{C}$ results in immediate cell death (Hennerbichler et al., 2007a). Cryopreservation with dimethylsulphoxide (DMSO) at $-80^{\circ} \mathrm{C}$ allows retention cells in the $\mathrm{AM}$ at approximately $50 \%$ for several months (Kubo et al., 2001). It has also been reported, though, that several angiogenic growth factors and cytokines are removed during crypreservation of the AM (Hennerbichler et al., 2007b). However, if the AM is cryopreserved in 50\% glycerol, the viability of AECs is lost (Kruse et al., 2000). In general, cell viability of the AM depends on the media composition and storage temperature of the preservation process. Sterilization with $\gamma$-rays has no significant effect on growth factor content in the human AM while removal of epithelium eliminates nearly all important growth factors (Branski et al., 2007). It has been shown that native, intact AM contains higher levels of EGF, KGF, HGF and bFGF compared to epithelially denuded AM (Koizumi et al., 2000), suggesting that these growth factors are predominantly present in the amniotic epithelium. In addition, TNF- $\alpha$, NGF, BDNF, noggin and activin has been also detected in AECs (Uchida et al., 2000; Koyano et al., 2002). Therefore the amniotic epithelium contains cytokines that play a crucial role in the microenvironmental niche of some progenitor cells. It was demonstrated that the resultant expanded epithelium on intact amniotic membrane indeed adopts a limbal epithelial phenotype whereas that on denuded amniotic membrane revealed a corneal epithelial phenotype (Grueterich et al., 2003). However, presence of an amniotic epithelium may hinder the uniform expansion of explants cultured on the membrane and delay the formation of strong hemidesmosomal attachment (Burman et al., 2004). Therefore, determining which AM preparation, intact or denude, is appropriate for TE depends on other conditions, including the type of cells or tissue is being used. Further studies are needed to elucidate the potential mechanisms of action.

The human AM is now widely used to reconstruct the ocular surface for the treatment of several conditions, including intractable epithelial defects, chemical burns, partial limbal cell deficiencies, ocular cicatricial pemphigoid, and Stevens-Johnson syndrome (Tseng et al., 1998; Azuara-Blanco et al., 1999; Tsubota et al., 1996; Chen et al., 2000). Several experimental studies have been performed using the AM as a scaffold. It has been reported that the ECM of the human amnion is an effective conduit for peripheral nerve regeneration and that the $\mathrm{AM}$ is a biodegradable scaffold with unique biochemical and mechanical characteristic for nerve regeneration (Mohammad et al., 2000; Mligiliche et al., 2002). It has also been demonstrated that denuded AM can be utilized as a feeder layer for some stem cells and may be used for neuronal differentiation (Miyamoto et al., 2004; Ueno et al., 2006; Meng et al., 2007). Denuded AM has been investigated as a carrier of chondrocytes, and it has been suggested that the AM can serve as a carrier matrix for cartilage regeneration (Jin et al., 2007). When epithelial and mesenchymal cells are seeded on a cellular scaffold created from the AM, the cells were highly interconnected and capable of penetrating the porous structure of the amnion scaffold. These experiments suggest a promising new approach for the repair of a prematurely ruptured foetal membrane (Portmann-Lanz et al., 2007). Cultivation and seeding of epithelial cells on an amnion scaffold is a frequently used method for ocular surface and skin reconstruction (Fatima et al., 2006; Yang et al., 2006; Capeans et al., 2003). And lastly, cultivation of endothelial cells on an AM scaffold has also been reported as a potential approach for vascular TE (Ishino et al., 2004; Tsai et al., 2007). A summary of potential applications of AM scaffolds for different tissues is summarized in Table 1. 


\section{Other properties of the amniotic membrane}

\section{Anti-inflammatory and anti-microbial}

Tissue engineered constructs often provoke an inflammatory reaction known as a foreign body reaction upon implantation. These implanted materials can be degradable or non-degradable. While inflammation can be good in some instances to trigger the healing of an injury, it can also lead to implant failure. Foreign body reactions evoke stimulation of giant cells and macrophages that produce cytokines and attract fibroblasts, leading to fibrosis. These fibroblasts are activated by the transforming growth factor (TGF)ß (Khouw et al., 1999).

The AM down-regulates TGF- $\beta$ and its receptor expression by fibroblasts and in doing so, reduce the risk of fibrosis. Therefore, an AM scaffold can modulate the healing of a wound by promoting tissue reconstruction rather than promoting scar tissue formation (Tseng et al., 1999; Lee et al., 2000).

There are several reports of the AM reducing inflammation. The AM stromal matrix markedly suppresses the expression of the potent pro-inflammatory cytokines, IL-1 $\alpha$ and IL-1 $\beta$ (Solomon et al., 2001). Matrix metalloproteases (MMPs) are expressed by infiltrating polymorphonuclear cells and macrophages. Natural inhibitors of MMPs have been found in the AM (Hao et al., 2000; Kim et al., 2000). Hyaluronic acid is a highmolecular-weight glycosaminoglycan that exists in large quantities in the AM and acts as a ligand for CD44, which is expressed on inflammatory cells and plays an important role in adhesion of inflammatory cells, including lymphocytes, to the AM stroma (Higa et al., 2005).

The $\beta$-defensins are a major group of anti-microbial peptides that are expressed at mucosal surfaces by epithelial cells and leukocytes, and are an integral part of the innate immune system (Krisanaprakornkit et al., 1998; Harder et al., 2000). The innate immune system has evolved to eliminate microorganisms upon entry into the tissues, creating antigens necessary to produce an adaptive immune response. ACEs also have the ability to produce $\beta$ defensins (King et al., 2007). The $\beta 3$-defensin is the predominant defensin in the amniotic epithelial (Buhimschi et al., 2004). In addition, 2 low-molecular-mass elastase inhibitors, secretory leukocyte proteinase inhibitor (SLPI) and elafin, are expressed in the AM (King et al., 2007; Buhimschi et al., 2004). In addition to their antiinflammatory properties, elafin and SLPI both have antimicrobial actions and act as components of the innate immune system to protect related surfaces from infection (King et al., 2003). Treatment of the AM with both lactoferrin and interleukin-1 receptor antagonists make the AM both anti-microbial and anti-inflammatory (Kanyshkova et al., 2001). Lactoferrin is a globular multifunctional protein, which has both anti-microbial and antiinflammatory effects, by serving as an antioxidant and an iron chelator in tissues (Gomes et al., 2005). Lactoferrin suppresses the production of interleukin- 6 in the amniotic fluid during amniotic infection (Kanyshkova et al., 2001). By contrast, the interleukin-1 receptor antagonist is a potent inhibitor of interleukin-1 and thus will suppress the inflammation mediated by interleukin-1 (Romero et al., 1994).

\section{Low immunogenicity}

Low risk of immunogenicity is an important component of creating a biocompatible scaffold for TE. Considering most ECM components in the creation of scaffolds are of xenogenic origin, (e.g. bovine type I collagen is harvested from Achilles tendon is perhaps the most commonly used xenogenic ECM component intended for therapeutic applications) it is important to consider the immunogenicity of the scaffold. Some experimental changes made to native biomaterials can result in an increased immune response upon transplantation. For example, methods of chemically cross-linking the ECM for purposes of increased material strength and slower in vivo degradation have uniformly resulted in a scaffold material that is less biocompatible than ECM that is preserved in its native state (Badylak, 2004).

In another example, the extraction of specific ECM components for therapeutic use involves the decellularization of mammalian tissue. An ECM scaffold alone (without the accompanying cells) and the potential degradation products might act as potential antigenic or inflammatory stimuli in vivo. Hence, the immunologic responses to the ECM alone are distinctly different than those observed when cells are embedded within the ECM and cell death and cell debris are components of the host response. In spite of the extensive measures taken to decellularize tissues in the preparation of ECM scaffolds, the complete elimination of all cell membrane and nuclear materials is very difficult and perhaps impossible. Hence, investigation into the immunogenicity of cellular components will also be important. For example, one of the major barriers to xenotransplantation in humans is the presence of natural antibodies to the terminal galactose alpha 1, 3 galactose (alpha-gal) epitope. This epitope is expressed on all mammalian cell membranes except those of human and old world primates. In humans, these naturally occurring antibodies can be of the $\operatorname{IgM}, \operatorname{IgG}$ or $\operatorname{IgA}$ isotype and often mediate hyper-acute or delayed rejection of implants (Sandrin et al., 1993; Schussler et al., 2001).

Use of the AM as a scaffold for tissue engineering will bypass the immunological complications of xenogenic biomaterials. Studying immune responses during pregnancy will be an important first step for the investigation of AM immunogenicity. One masterpiece of creation manifests itself in pregnancy. Considering that half of the zygote is composed of the father's DNA, the foetus has semi-allogenic antigens recognized by the mother. However, the pregnancy is established normally in most cases, without rejection. There may be several mechanisms involved with protecting the foetus from a maternal immune response. Both local and systemic nonspecific suppressor mechanisms have been described which may down-regulate maternal immune responses without significantly impairing the ability to fight infections. The placental barrier restricts the traffic of cytotoxic cells to the foetus, and therefore, cytotoxic antibodies are removed by the placental before they reach the foetal circulation. The major factor, which appears to prevent the rejection of the trophoblast, is its expression of HLA-G. In contrast to HLA-A and -B class I genes, 
which are down regulated in human trophoblast cells, nonpolymorphic class I molecules including HLA-G are expressed in extra-villous cytotrophoblast and also in amnion cells and amniotic fluid. The role of the highly polymorphic classical class I molecules HLA-A, -B, -C, is to induce a specific immune response by presenting peptide antigens to $\mathrm{T}$ cells. In contrast, the HLA-G is thought to be involved in the induction of immune tolerance by acting as ligand for inhibitory receptors present on NK cells and macrophages (Sargent, 1993; Szekeres-Bartho, 2002).

As the AM is originally foetal tissue, all information described above holds true. As previously mentioned, AECs do not express HLA-A, -B, -D, and -DR antigens on the cell surface, but express HLA-G on their surfaces, suggesting that acute rejection would not occur after transplantation (Hori et al., 2006). It has been also reported that HLA-G gene is up-regulated in conjunctival and limbal epithelial cells when these cells are cultured on denuded AM (Higa et al., 2006). Although the immunogenicity of the AM is controversial, in general, it is believed that the AM possesses low immunogenicity (Hori et al., 2006). In addition, it is generally thought that the immunogenicity of cryopreserved AM tissue is less than that of fresh AM tissues and that cryopreserved cells are expected to be nonviable. This approach guides some researches to use of cryopreserved AM instead of fresh AM (Kubo et al., 2001).

\section{Mechanical properties}

Often a graft site must bear loads at or close to physiological levels very soon after transplantation. Internal fixation often provides the necessary early stability. However, in some tissues, the scaffold must bear or share substantial load early after transplantation. In addition, because mechanical signals are important mediators of differentiation for some progenitor cells, the scaffold must create an appropriate environment throughout the site where new tissue is desired. Increased stiffness enhances scaffold strength necessary to resist stress induced during the growth of tissue (Kim et al., 1999; Sikavitsas et al., 2001). The elasticity, stiffness and other biomechanical properties of the ECM depend on the variation in its ingredients, such as collagen, proteoglycan and elastin (Kiviranta et al., 2006).

Most research performed, up to now, on the biomechanical properties of the AM has been for the investigation of premature rupture of the foetal membrane (PROM). PROM is defined as rupture of chorioamnion prior to the onset of labour. The foetal membrane must bear the load of hydrostatic pressure from amniotic fluid during gestation. In addition to chronic load of during normal pregnancy, foetal membranes must also likely bear repetitive minor loads, such as Braxton-hicks contractions (Bittar et al., 1996). The AM is approximately $20 \%$ of the chorioamnion thickness at term, but dominates the mechanical responses of the bi-layer, with both stiffness and strength by an order of magnitude greater than the chorion layer. Hence, the strength of the intact chorioamniotic membrane is primarily determined by the AM (Oxlund et al., 1990). Because of mechanical importance in vivo, the foetal membrane, and particularly the amnion layer, has been the focus of a number of in vitro mechanical studies. With these mechanical studies, the baseline mechanical properties of a soft tissue membrane can be assessed. The baseline properties in isolation are of interest primarily for in vitro mechanical modelling purposes and for matching in the case of TE replacement (Oyen et al., 2005; Calvin and Oyen, 2007).

The AM demonstrates a mechanical response that is inherently time-dependent, described as "viscoelastic". (Lavery and Miller, 1997; Oyen et al., 2005; Calvin and Oyen, 2007). Viscoelasticity is a critical property of scaffolding in a majority of tissues. For example, very stiff scaffolds lack the viscoelastcity of arteries, promoting intimal hyperplasia and occlusion (Sarkar et al., 2007). Although, it has been shown that preterm AM has a greater mechanical integrity than term AM, the stiffness of term $\mathrm{AM}$ is more reasonable for a majority of tissue engineering protocols (Mohammad et al., 2000; Jin et al., 2007; He et al., 2002; Wilshaw et al., 2006). One measure of elasticity is the Young's modulus, which is normally applied in mechanical physics and is defined as the ratio of applied stress to strain. It reported that Young's modulus of preterm (26-36 weeks) human AM is $3.6 \mathrm{MPa}$, whereas this modulus for term (36-40 weeks) human AM is $2.29 \mathrm{MPa}$ (Benson-Martin et al., 2006). This mechanical change may be related to the collagen content, although there are conflicting reports regarding whether the amnion collagen content actually decreases with gestational age (BensonMartin et al., 2006; Manabe et al., 1991). It is also worth noting that elastin, which is detected in the foetal amnion, is proposed to provide the molecular basis for elasticity in the AM (Hieber et al., 1997).

\section{Amniotic membrane: hype or hope}

Despite all of the advantages of AM for TE, some pitfalls must be overcome before the AM is used therapeutically for TE. The AM is a biological-derived material and concomitant are the same problems of other biological material applications. For instance, transmission of infectious diseases is always a risk associated with human organ and tissue transplantation. Thus, the same precautions and safety criteria applied to organ transplantation have to be adhered in the application of AM. Potential donors need to be screened effectively for any risk factors that might render them unsuitable for donation. A review of relevant medical records to ensure freedom from risk factors for and clinical evidence of HIV, hepatitis $\mathrm{B}$, hepatitis $\mathrm{C}, \mathrm{CMV}$, syphilis, and other possible infections, should be carried out. There is a slight possibility that the donor may be in the "window period" of infection. Hence, even if serological tests are negative, it is advisable to repeat the investigations after 6 months. The AM can be preserved at $-80^{\circ} \mathrm{C}$ until samples found negative of any infectious diseases (Fernandes et al., 2005).

A placenta obtained shortly after elective Caesarean delivery is the preferred source of an AM. Placentas from vaginal deliveries or subsequent to PROM are known to be contaminated and therefore unsuitable for transplantation. 
The comprehensive mapping of foetal membranes at term, detected an area of the membrane that exhibited unique morphological features, which were only found within a restricted area, termed as "zone of altered morphology" (ZAM). This feature includes structural weaknesses and a marked disruption of the connective tissue layers as well as a marked reduction of the thickness and cellularity of the membrane (Malak and Bell, 1994). Apoptosis of cells and degradation of basement membrane by MMPs in ZAM are the proposed mechanism for these features (Moore et al., 2006). Due to decreased integrity and increased apoptosis of cells in this region, use of the ZAM is not preferred.

As mentioned, AECs have many characteristics similar to stem cells, but one of the most important properties of stem cells is that they survive freeze-thaw. In contrast, it has been shown that the viability of AECs decrease after freezing (Kubo et al., 2001). Hence, if a stable and longterm supply of AECs is realized, it could be applied to the transplantation therapy for a wide variety of diseases.

There are other problems that might arise with the use of the AM for tissue engineering. The AM is a thin structure and has its technical limitations with regards to suturing. A new approach might include the use of glues as a substitute for suturing (Szurman et al., 2006).

In the past decade, the AM has been greatly used in the field of ophthalmology. Therefore, much of what we know is derived from its uses in this field. A comparison of its ophthalmologic uses with its potential uses with other tissues that have different characteristics (e.g., different mechanical properties) will be necessary.

Despite the few obstacles mentioned above, the future of the AM in applications such as TE is very exciting. However, further work is needed to determine the full potential of the AM for the uses described in this review.

\section{Conclusions}

The AM has many characteristics, which make it potentially suitable for use in TE. The epithelial layer of the AM includes cells that have similar characteristics to stem cells. As described, these cells express pluripotent markers of stem cells and can be differentiated into all three germ layers. AECs are not, however, tumourigenic upon transplantation. These cells have no need for a feeder layer throughout their cultivation. In addition, there are many other advantages that suggest AECs are an excellent source of cells for TE.

The AM can act as a scaffold for TE. The ECM components of the basement membrane from the AM include collagen, fibronectin, laminin and other proteoglycans important for overlying cell growth. These ingredients are the ligands for integrin receptors, and hence, have a great role in cell adhesion during the cell seeding protocol. Other properties of the AM include antiinflammation, anti-fibrosis, anti-scaring, anti-microbial, low immunogenicity and reasonable mechanical property, which are all important for use in TE.

However, the AM, like other biological material, has some problems described above and its uses should be carefully carried out. Meanwhile, the manifestation of its many different uses in other future studies will facilitate in its application in TE.

\section{Acknowledgement}

The authors would like to thank Jaklyn Schwarz for her comments.

\section{References}

Aplin AE (2003) Cell adhesion molecule regulation of nucleocytoplasmic trafficking. FEBS Lett 534: 11-14.

Azuara-Blanco A, Pillai CT, Dua HS (1999) Amniotic membrane transplantation for ocular surface reconstruction. Br J Ophthalmol 83: 399-402.

Bacakova L, Filova E, Rypacek F, Svorcik V, Stary V (2004) Cell adhesion on artificial materials for tissue engineering. Physiol Res 53 Suppl 1: S35-45.

Badylak SF (2004) Xenogeneic extracellular matrix as a scaffold for tissue reconstruction. Transpl Immunol 12: 367-377.

Baguneid MS, Seifalian AM, Salacinski HJ, Murray D, Hamilton G, Walker MG (2006) Tissue engineering of blood vessels. Br J Surg 93: 282-290.

Benson-Martin J, Zammaretti P, Bilic G, Schweizer T, Portmann-Lanz B, Burkhardt T, Zimmermann R, Ochsenbein-Kolble N (2006) The Young's modulus of fetal preterm and term amniotic membranes. Eur J Obstet Gynecol Reprod Biol 128: 103-107.

Bittar RE, Yamasaki AA, Sasaki S, Zugaib M (1996) Cervical fetal fibronectin in patients at increased risk for preterm delivery. Am J Obstet Gynecol 175: 178-181.

Bobbert M (2006) Ethical questions concerning research on human embryos, embryonic stem cells and chimeras. Biotechnol J 1: 1352-1369.

Branski LK, Kulp G, Jeschke MG, Norbury WB, Herndon DN (2007) Amniotic membrane as wound coverage: The effects of irradiation and different processing methods on growth factor content. J Surg Res 137: 339 .

Buhimschi IA, Jabr M, Buhimschi CS, Petkova AP, Weiner CP, Saed GM (2004) The novel antimicrobial peptide beta3-defensin is produced by the amnion: a possible role of the fetal membranes in innate immunity of the amniotic cavity. Am J Obstet Gynecol 191: 16781687.

Burman S, Tejwani S, Vemuganti GK, Gopinathan U, Sangwan VS (2004) Ophthalmic applications of preserved human amniotic membrane: a review of current indications. Cell Tissue Bank 5: 161-175.

Burridge K, Chrzanowska-Wodnicka M (1996) Focal adhesions, contractility, and signaling. Annu Rev Cell Dev Biol 12: 463-518.

Calvin SE, Oyen ML (2007) Microstructure and mechanics of the chorioamnion membrane with an emphasis on fracture properties. Ann N Y Acad Sci 1101: 166-185. 
Capeans C, Pineiro A, Pardo M, Sueiro-Lopez C, Blanco MJ, Dominguez F, Sanchez-Salorio M (2003) Amniotic membrane as support for human retinal pigment epithelium (RPE) cell growth. Acta Ophthalmol Scand 81: 271-277.

Chai C, Leong KW (2007) Biomaterials approach to expand and direct differentiation of stem cells. Mol Ther 15: $467-480$.

Chambers I, Colby D, Robertson M, Nichols J, Lee S, Tweedie S, Smith A (2003) Functional expression cloning of Nanog, a pluripotency sustaining factor in embryonic stem cells. Cell 113: 643-655.

Chen HJ, Pires RT, Tseng SC (2000) Amniotic membrane transplantation for severe neurotrophic corneal ulcers. Br J Ophthalmol 84: 826-833.

Daheron L, Opitz SL, Zaehres H, Lensch WM, Andrews PW, Itskovitz-Eldor J, Daley GQ (2004) LIF/ STAT3 signaling fails to maintain self-renewal of human embryonic stem cells. Stem Cells 22: 770-778.

Davis J W (1910) Skin transplantation with a review of 550 cases at the Johns Hopkins Hospital. Johns Hopkins Med J 15: 307.

Fatima A, Sangwan VS, Iftekhar G, Reddy P, Matalia H, Balasubramanian D, Vemuganti GK (2006) Technique of cultivating limbal derived corneal epithelium on human amniotic membrane for clinical transplantation. J Postgrad Med 52: 257-261.

Fernandes M, Sridhar MS, Sangwan VS, Rao GN (2005) Amniotic membrane transplantation for ocular surface reconstruction. Cornea 24: 643-653.

Geiger B, Bershadsky A, Pankov R, Yamada KM (2001) Transmembrane crosstalk between the extracellular matrix-cytoskeleton crosstalk. Nat Rev Mol Cell Biol 2: 793-805.

Gomes JA, Romano A, Santos MS, Dua HS (2005) Amniotic membrane use in ophthalmology. Curr Opin Ophthalmol 16: 233-240.

Grueterich M, Espana EM, Tseng SC (2003) Ex vivo expansion of limbal epithelial stem cells: amniotic membrane serving as a stem cell niche. Surv Ophthalmol 48: $631-646$.

Hao Y, Ma DH, Hwang DG, Kim WS, Zhang F (2000) Identification of antiangiogenic and antiinflammatory proteins in human amniotic membrane. Cornea 19: 348352.

Harder J, Meyer-Hoffert U, Teran LM, Schwichtenberg L, Bartels J, Maune S, Schroder JM (2000) Mucoid Pseudomonas aeruginosa, TNF-alpha, and IL-1beta, but not IL-6, induce human beta-defensin-2 in respiratory epithelia. Am J Respir Cell Mol Biol 22: 714-721.

He Q, Li Q, Chen B, Wang Z (2002) Repair of flexor tendon defects of rabbit with tissue engineering method. Chin J Traumatol 5: 200-208.

Heng BC, Liu H, Cao T (2004) Feeder cell density-a key parameter in human embryonic stem cell culture. In Vitro Cell Dev Biol Anim 40: 255-257.

Hennerbichler S, Reichl B, Pleiner D, Gabriel C, Eibl J, Redl H (2007a) The influence of various storage conditions on cell viability in amniotic membrane. Cell Tissue Bank 8: 1-8.
Hennerbichler S, Reichl B, Wolbank S, Eibl J, Gabriel C, Redl H (2007b) Cryopreserved amniotic membrane releases angiogenic factors. Wound Rep Reg 15: A51.

Hieber AD, Corcino D, Motosue J, Sandberg LB, Roos PJ, Yu SY, Csiszar K, Kagan HM, Boyd CD, BryantGreenwood GD (1997) Detection of elastin in the human fetal membranes: proposed molecular basis for elasticity. Placenta 18: 301-312.

Higa K, Shimmura S, Shimazaki J, Tsubota K (2005) Hyaluronic acid-CD44 interaction mediates the adhesion of lymphocytes by amniotic membrane stroma. Cornea 24 : 206-212.

Higa K, Shimmura S, Shimazaki J, Tsubota K (2006) Ocular surface epithelial cells up-regulate HLA-G when expanded in vitro on amniotic membrane substrates. Cornea 25: 715-721.

Hori J, Wang M, Kamiya K, Takahashi H, Sakuragawa $\mathrm{N}$ (2006) Immunological characteristics of amniotic epithelium. Cornea 25: S53-S58.

Ilancheran S, Michalska A, Peh G, Wallace EM, Pera M, Manuelpillai U (2007) Stem cells derived from human fetal membranes display multilineage differentiation potential. Biol Reprod 77: 577-588.

Ishino Y, Sano Y, Nakamura T, Connon CJ, Rigby H, Fullwood NJ, Kinoshita S (2004) Amniotic membrane as a carrier for cultivated human corneal endothelial cell transplantation. Invest Ophthalmol Vis Sci 45: 800-806.

Jin CZ, Park SR, Choi BH, Lee KY, Kang CK, Min $\mathrm{BH}$ (2007) Human amniotic membrane as a delivery matrix for articular cartilage repair. Tissue Eng 13: 693-702.

Kanyshkova TG, Buneva VN, Nevinsky GA (2001) Lactoferrin and its biological functions. Biochemistry (Mosc) 66: 1-7.

Khouw IM, van Wachem PB, Plantinga JA, Vujaskovic Z, Wissink MJ, de Leij LF, van Luyn MJ (1999) TGF-beta and $b F G F$ affect the differentiation of proliferating porcine fibroblasts into myofibroblasts in vitro. Biomaterials 20: 1815-1822.

Kim BS, Nikolovski J, Bonadio J, Mooney DJ (1999) Cyclic mechanical strain regulates the development of engineered smooth muscle tissue. Nat Biotechnol 17: 979983.

Kim JS, Kim JC, Na BK, Jeong JM, Song CY (2000) Amniotic membrane patching promotes healing and inhibits proteinase activity on wound healing following acute corneal alkali burn. Exp Eye Res 70: 329-337.

King AE, Critchley HO, Sallenave JM, Kelly RW (2003) Elafin in human endometrium: an antiprotease and antimicrobial molecule expressed during menstruation. J Clin Endocrinol Metab 88: 4426-4431.

King AE, Paltoo A, Kelly RW, Sallenave JM, Bocking AD, Challis JR (2007) Expression of natural antimicrobials by human placenta and fetal membranes. Placenta 28: 161169.

Kiviranta P, Rieppo J, Korhonen RK, Julkunen P, Toyras J, Jurvelin JS (2006) Collagen network primarily controls Poisson's ratio of bovine articular cartilage in compression. J Orthop Res 24: 690-699.

Knight MA, Evans GR (2004) Tissue engineering: progress and challenges. Plast Reconstr Surg 114: 26E37E. 
Koizumi NJ, Inatomi TJ, Sotozono CJ, Fullwood NJ, Quantock AJ, Kinoshita S (2000) Growth factor mRNA and protein in preserved human amniotic membrane. Curr Eye Res 20: 173-177.

Kosuga M, Takahashi S, Sasaki K, Enosawa S, Li XK, Okuyama S, Fujino M, Suzuki S, Yamada M, Matsuo N, Sakuragawa N, Okuyama T (2000) Phenotype correction in murine mucopolysaccharidosis type VII by transplantation of human amniotic epithelial cells after adenovirus-mediated gene transfer. Cell Transplant 9: 687692.

Koyano S, Fukui A, Uchida S, Yamada K, Asashima M, Sakuragawa N (2002) Synthesis and release of activin and noggin by cultured human amniotic epithelial cells. Dev Growth Differ 44: 103-112.

Krisanaprakornkit S, Weinberg A, Perez CN, Dale BA (1998) Expression of the peptide antibiotic human betadefensin 1 in cultured gingival epithelial cells and gingival tissue. Infect Immun 66: 4222-4228.

Kruse FE, Joussen AM, Rohrschneider K, You L, Sinn B, Baumann J, Volcker HE (2000) Cryopreserved human amniotic membrane for ocular surface reconstruction. Graefes Arch Clin Exp Ophthalmol 238: 68-75.

Kubo M, Sonoda Y, Muramatsu R, Usui M (2001) Immunogenicity of human amniotic membrane in experimental xenotransplantation. Invest Ophthalmol Vis Sci 42: 1539-1546.

Langer R, Vacanti JP (1993) Tissue engineering. Science 260: 920-926.

Lavery JP, Miller CE (1977) The viscoelastic nature of chorioamniotic membranes. Obstet Gynecol 50: 467472 .

Lee SB, Li DQ, Tan DT, Meller DC, Tseng SC (2000) Suppression of TGF-beta signaling in both normal conjunctival fibroblasts and pterygial body fibroblasts by amniotic membrane. Curr Eye Res 20: 325-334.

Lefebvre S, Adrian F, Moreau P, Gourand L, Dausset J, Berrih-Aknin S, Carosella ED, Paul P (2000) Modulation of HLA-G expression in human thymic and amniotic epithelial cells. Hum Immunol 61: 1095-1101.

Lei T, Jacob S, Ajil-Zaraa I, Dubuisson JB, Irion O, Jaconi M, Feki A (2007) Xeno-free derivation and culture of human embryonic stem cells: current status, problems and challenges. Cell Res 17: 682-688.

Malak TM, Bell SC (1994) Structural characteristics of term human fetal membranes: a novel zone of extreme morphological alteration within the rupture site. Br J Obstet Gynaecol 101: 375-386.

Mallon BS, Park KY, Chen KG, Hamilton RS, McKay RD (2006) Toward xeno-free culture of human embryonic stem cells. Int J Biochem Cell Biol 38: 1063-1075.

Manabe Y, Himeno N, Fukumoto M (1991) Tensile strength and collagen content of amniotic membrane do not change after the second trimester or during delivery. Obstet Gynecol 78: 24-27.

Mano JF, Silva GA, Azevedo HS, Malafaya PB, Sousa RA, Silva SS, Boesel LF, Oliveira JM, Santos TC, Marques AP, Neves NM, Reis RL (2007) Natural origin biodegradable systems in tissue engineering and regenerative medicine: present status and some moving trends. J R Soc Interface 4: 999-1030.
Martin MJ, Muotri A, Gage F, Varki A (2005) Human embryonic stem cells express an immunogenic nonhuman sialic acid. Nat Med 11: 228-232.

Meng XT, Chen D, Dong ZY, Liu JM (2007) Enhanced neural differentiation of neural stem cells and neurite growth by amniotic epithelial cell co-culture. Cell Biol Int 31: 691-698.

Miki T, Lehmann T, Cai H, Stolz DB, Strom SC (2005) Stem cell characteristics of amniotic epithelial cells. Stem Cells 23: 1549-1559.

Miki T, Mitamura K, Ross MA, Stolz DB, Strom SC (2007a) Identification of stem cell marker-positive cells by immunofluorescence in term human amnion. J Reprod Immunol 75:91-96

Miki T, Marongiu F, Ellis E, Strom S (2007b) Isolation of amniotic epithelial stem cells. Curr Protoc Setm Cell Biol (in press).

Mitjavila-Garcia MT, Simonin C, Peschanski M (2005) Embryonic stem cells: meeting the needs for cell therapy. Adv Drug Deliv Rev 57: 1935-1943.

Miyamoto K, Hayashi K, Suzuki T, Ichihara S, Yamada T, Kano Y, Yamabe T, Ito Y (2004) Human placenta feeder layers support undifferentiated growth of primate embryonic stem cells. Stem Cells 22: 433-440.

Mligiliche N, Endo K, Okamoto K, Fujimoto E, Ide C (2002) Extracellular matrix of human amnion manufactured into tubes as conduits for peripheral nerve regeneration. J Biomed Mater Res 63: 591-600.

Mohammad J, Shenaq J, Rabinovsky E, Shenaq S (2000) Modulation of peripheral nerve regeneration: a tissue-engineering approach. The role of amnion tube nerve conduit across a 1-centimeter nerve gap. Plast Reconstr Surg 105: 660-666.

Moiseeva EP (2001) Adhesion receptors of vascular smooth muscle cells and their functions. Cardiovasc Res 52: 372-386.

Moore RM, Mansour JM, Redline RW, Mercer BM, Moore JJ (2006) The physiology of fetal membrane rupture: insight gained from the determination of physical properties. Placenta 27: 1037-1051.

Mosquera A, Fernandez JL, Campos A, Goyanes VJ, Ramiro-Diaz J, Gosalvez J (1999) Simultaneous decrease of telomere length and telomerase activity with ageing of human amniotic fluid cells. J Med Genet 36: 494-496.

Murdoch AD, Dodge GR, Cohen I, Tuan RS, Iozzo RV (1992) Primary structure of the human heparan sulfate proteoglycan from basement membrane (HSPG2/ perlecan). A chimeric molecule with multiple domains homologous to the low density lipoprotein receptor, laminin, neural cell adhesion molecules, and epidermal growth factor. J Biol Chem 267: 8544-8557.

Naughton GK (2002) From lab bench to market: critical issues in tissue engineering. Ann N Y Acad Sci 961: 372385 .

Oxlund H, Helmig R, Halaburt JT, Uldbjerg N (1990) Biomechanical analysis of human chorioamniotic membranes. Eur J Obstet Gynecol Reprod Biol 34: 247 255.

Oyen ML, Cook RF, Stylianopoulos T, Barocas VH, Calvin SE, Landers DV (2005) Uniaxial and biaxial 
mechanical behavior of human amnion. J Mater Res 20: 2902-2909.

Parolini O, Soncini, M. (2006) Human placenta: a source of progenitor/stem cells? J Reproduktionsmed Endokrinol 3: 117-126.

Parry S, Strauss JF, 3rd (1998) Premature rupture of the fetal membranes. N Engl J Med 338: 663-670.

Portmann-Lanz CB, Ochsenbein-Kolble N, Marquardt K, Luthi U, Zisch A, Zimmermann R (2007) Manufacture of a cell-free amnion matrix scaffold that supports amnion cell outgrowth in vitro. Placenta 28: 6-13.

Reubinoff BE, Pera MF, Fong CY, Trounson A, Bongso A (2000) Embryonic stem cell lines from human blastocysts: somatic differentiation in vitro. Nat Biotechnol 18: $399-404$.

Romero R, Gomez R, Galasso M, Mazor M, Berry SM, Quintero RA, Cotton DB (1994) The natural interleukin1 receptor antagonist in the fetal, maternal, and amniotic fluid compartments: the effect of gestational age, fetal gender, and intrauterine infection. Am J Obstet Gynecol 171: 912-921.

Sakuragawa N, Tohyama J, Yamamoto H (1995) Immunostaining of human amniotic epithelial cells: possible use as a transgene carrier in gene therapy for inborn errors of metabolism. Cell Transplant 4: 343-346.

Sandrin MS, Vaughan HA, Dabkowski PL, McKenzie IF (1993) Anti-pig IgM antibodies in human serum react predominantly with Gal(alpha 1-3)Gal epitopes. Proc Natl Acad Sci U S A 90: 11391-11395.

Sargent IL (1993) Maternal and fetal immune responses during pregnancy. Exp Clin Immunogenet 10: 85-102.

Sarkar S, Sales KM, Hamilton G, Seifalian AM (2007) Addressing thrombogenicity in vascular graft construction. J Biomed Mater Res B Appl Biomater 82: 100-108.

Schussler O, Shen M, Shen L, Carpentier SM, Kaveri S, Carpentier A (2001) Effect of human immunoglobulins on the immunogenicity of porcine bioprostheses. Ann Thorac Surg 71: S396-400.

Sikavitsas VI, Temenoff JS, Mikos AG (2001) Biomaterials and bone mechanotransduction. Biomaterials 22: 2581-2593.

Sniadecki NJ, Desai RA, Ruiz SA, Chen CS (2006) Nanotechnology for cell-substrate interactions. Ann Biomed Eng 34: 59-74.

Solomon A, Rosenblatt M, Monroy D, Ji Z, Pflugfelder SC, Tseng SC (2001) Suppression of interleukin 1alpha and interleukin 1beta in human limbal epithelial cells cultured on the amniotic membrane stromal matrix. Br J Ophthalmol 85: 444-449.

Solomon A, Meller D, Prabhasawat P, John T, Espana EM, Steuhl KP, Tseng SC (2002) Amniotic membrane grafts for nontraumatic corneal perforations, descemetoceles, and deep ulcers. Ophthalmology 109: 694703.

Szekeres-Bartho J (2002) Immunological relationship between the mother and the fetus. Int Rev Immunol 21: 471-495.

Szurman P, Warga M, Grisanti S, Roters S, Rohrbach JM, Aisenbrey S, Kaczmarek RT, Bartz-Schmidt KU (2006) Sutureless amniotic membrane fixation using fibrin glue for ocular surface reconstruction in a rabbit model. Cornea 25: 460-466.

Takashima S, Ise H, Zhao P, Akaike T, Nikaido T (2004) Human amniotic epithelial cells possess hepatocyte-like characteristics and functions. Cell Struct Funct 29: 73-84.

Tamagawa T, Ishiwata I, Saito S (2004) Establishment and characterization of a pluripotent stem cell line derived from human amniotic membranes and initiation of germ layers in vitro. Hum Cell 17: 125-130.

Terada S, Matsuura K, Enosawa S, Miki M, Hoshika A, Suzuki S, Sakuragawa N (2000) Inducing proliferation of human amniotic epithelial (HAE) cells for cell therapy. Cell Transplant 9: 701-704.

Thomson JA, Itskovitz-Eldor J, Shapiro SS, Waknitz MA, Swiergiel JJ, Marshall VS, Jones JM (1998) Embryonic stem cell lines derived from human blastocysts. Science 282: 1145-1147.

Tsai SH, Liu YW, Tang WC, Zhou ZW, Hwang CY, Hwang GY, Ou BR, Hu CP, Yang VC, Chen JK (2007) Characterization of porcine arterial endothelial cells cultured on amniotic membrane, a potential matrix for vascular tissue engineering. Biochem Biophys Res Commun 357: 984-990.

Tseng SC, Prabhasawat P, Barton K, Gray T, Meller D (1998) Amniotic membrane transplantation with or without limbal allografts for corneal surface reconstruction in patients with limbal stem cell deficiency. Arch Ophthalmol 116: 431-441.

Tseng SC, Li DQ, Ma X (1999) Suppression of transforming growth factor-beta isoforms, TGF-beta receptor type II, and myofibroblast differentiation in cultured human corneal and limbal fibroblasts by amniotic membrane matrix. J Cell Physiol 179: 325-335.

Tsubota K, Satake Y, Ohyama M, Toda I, Takano Y, Ono M, Shinozaki N, Shimazaki J (1996) Surgical reconstruction of the ocular surface in advanced ocular cicatricial pemphigoid and Stevens-Johnson syndrome. Am J Ophthalmol 122: 38-52.

Ucakhan OO, Koklu G, Firat E (2002) Nonpreserved human amniotic membrane transplantation in acute and chronic chemical eye injuries. Cornea 21: 169-172.

Uchida S, Inanaga Y, Kobayashi M, Hurukawa S, Araie M, Sakuragawa N (2000) Neurotrophic function of conditioned medium from human amniotic epithelial cells. J Neurosci Res 62: 585-590.

Ueno M, Matsumura M, Watanabe K, Nakamura T, Osakada F, Takahashi M, Kawasaki H, Kinoshita S, Sasai Y (2006) Neural conversion of ES cells by an inductive activity on human amniotic membrane matrix. Proc Natl Acad Sci U S A 103: 9554-9559.

Vunjak-Novakovic G, Obradovic B, Martin I, Bursac PM, Langer R, Freed LE (1998) Dynamic cell seeding of polymer scaffolds for cartilage tissue engineering. Biotechnol Prog 14: 193-202.

Walgenbach KJ, Voigt M, Riabikhin AW, Andree C, Schaefer DJ, Galla TJ, Bjorn G (2001) Tissue engineering in plastic reconstructive surgery. Anat Rec 263: 372-378.

Wilshaw SP, Kearney JN, Fisher J, Ingham E (2006) Production of an acellular amniotic membrane matrix for use in tissue engineering. Tissue Eng 12: 2117-2129. 
Yang L, Shirakata Y, Shudou M, Dai X, Tokumaru S, Hirakawa S, Sayama K, Hamuro J, Hashimoto K (2006) New skin-equivalent model from de-epithelialized amnion membrane. Cell Tissue Res 326: 69-77.

Yang S, Leong KF, Du Z, Chua CK (2001) The design of scaffolds for use in tissue engineering. Part I. Traditional factors. Tissue Eng 7: 679-689.

Young MJ, Borras T, Walter M, Ritch R (2005) Tissue bioengineering: potential applications to glaucoma. Arch Ophthalmol 123: 1725-1731.

\section{Discussion with Reviewers}

M. Stoddart: How many $\mathrm{cm}^{2}$ can be acquired from one placenta?

Authors: The whole area of the human AM depends on gestational week. The surface area at term approximates $1300-1500 \mathrm{~cm}^{2}$. By considering the number of Caesarean sections that are performed in a year (e.g., more than 1 million in United States), it seems that the AM would be a good source for a human clinical setting in this era.

M. Stoddart: What is known of the immunological state of the cells once they have been differentiated into the required cell type?

Authors: Immunogenicity of the AECs after differentiation is depending on the type of target differentiated cells. It has been shown that upon differentiation of the AECs into pancreatic and hepatic lineages, the expression of HLA class IA antigens(but not HLA class II) increase in these cells. Whereas, following differentiation into cardiomyocytic cells, there were no changes in expression of HLA class IA (Ilancheran et al., 2007). These results suggest that differentiation may affect immunological state of AECs. On the other hand, AECs also secrete immunosuppressive factors that could facilitate successful use of these cells. It seems that both mentioned factors would be determinants of immunogenicity in differentiated AECs.

M. Stoddart: The authors should comment how could such a thin membrane be used to engineer tissue bulkier than the ocular membrane. When using membrane for larger TE constructs would the AM form one placenta be enough or would they need to be pooled?

Authors: The reviewer's comment is correct. The amnion is a thin membrane that make limitations to use it, so most studies have been carried out in ophthalmological fields. However, the AM has also been used for neural and skin regeneration as well as other tissues, as described in the text. In our lab, we have used the AM as a scaffold for vascular tissue engineering (unpublished data). In this study, amniotic membrane constructed conduits were interposed to external jugular vein of sheep by end-to-end anastomosis. Up to 24 weeks, grafts were completely patent with normal endothelialization and displayed no sign of stenosis. This suggests that the AM can be a proper alternative for prosthetic biomaterials.

On the other hand, the multilayer AM has been used for deep ulceration by some investigators. In this method, multiple layers of AM have been overlaid to fill deep ulcers. This method can be a good clue for construction of thicker tissues from AM (Prabhasawat et al., 2001).

\section{Additional Reference}

Prabhasawat P, Tesavibul N, Komolsuradej W (2001) Single and multilayer amniotic membrane transplantation for persistent corneal epithelial defect with and without stromal thinning and perforation. Br J Ophthalmol 85: 1455-1463. 